\title{
Evaluating the effect of rain on SeaWinds scatterometer measurements
}

David G. Long

Brigham Young University - Provo, long@ee.byu.edu

David Draper

Brigham Young University - Provo

Follow this and additional works at: https://scholarsarchive.byu.edu/facpub

Part of the Electrical and Computer Engineering Commons

\section{Original Publication Citation}

Draper, D. W., and D. G. Long (2004), Evaluating the effect of rain on SeaWinds scatterometer measurements, J. Geophys. Res., 109, C02005, doi:10.1029/2002JC001741.

\section{BYU ScholarsArchive Citation}

Long, David G. and Draper, David, "Evaluating the effect of rain on SeaWinds scatterometer measurements" (2004). Faculty Publications. 1986.

https://scholarsarchive.byu.edu/facpub/1986

This Peer-Reviewed Article is brought to you for free and open access by BYU ScholarsArchive. It has been accepted for inclusion in Faculty Publications by an authorized administrator of BYU ScholarsArchive. For more information, please contact ellen_amatangelo@byu.edu. 


\title{
Evaluating the effect of rain on SeaWinds scatterometer measurements
}

\author{
David W. Draper and David G. Long \\ Department of Electrical and Computer Engineering, Brigham Young University, Provo, Utah, USA \\ Received 9 December 2002; revised 20 October 2003; accepted 12 November 2003; published 12 February 2004.
}

[1] A simple wind/rain backscatter model is used with co-located precipitation radar (PR) data from the Tropical Rainfall Measuring Mission (TRMM) satellite to evaluate the effect of rain on SeaWinds on QuikSCAT $\sigma^{\circ}$ observations. The model incorporates wind-induced surface scattering, the surface rain perturbation, and atmospheric rain attenuation and scattering. The co-located PR measurements afford direct computation of SeaWinds-scale averaged rain rate and atmospheric rain attenuation and scattering. An estimate of the wind-induced surface backscatter is computed via numerical weather prediction (NWP) winds. By synergistically combining the SeaWinds, NWP, and PR data, estimates of surface rain perturbation and combined surface/atmospheric scattering are made as a function of PR-derived rain rate. The scattering from rain is dominated mainly by the surface perturbation low rain rates, and by atmospheric scattering at high rain rates. The backscatter model estimates $94 \%$ of the observed rain-contaminated SeaWinds on QuikSCAT $\sigma^{\circ}$ values to within $3 \mathrm{~dB}$. Using the model, the conditions are determined for which it is possible to estimate rain from scatterometer measurements and where wind retrieval is not possible. INDEX TERMS: 3360 Meteorology and Atmospheric Dynamics: Remote sensing; 3354 Meteorology and Atmospheric Dynamics: Precipitation (1854); 3394 Meteorology and Atmospheric Dynamics: Instruments and techniques; 4275 Oceanography: General: Remote sensing and electromagnetic processes (0689); 4504 Oceanography: Physical: Air/sea interactions (0312); KEYWORDS: rain estimation, SeaWinds, scatterometry

Citation: Draper, D. W., and D. G. Long (2004), Evaluating the effect of rain on SeaWinds scatterometer measurements, J. Geophys. Res., 109, C02005, doi:10.1029/2002JC001741.

\section{Introduction}

[2] The SeaWinds on QuikSCAT scatterometer, launched in 1999 by NASA, provides wide coverage of instantaneous ocean vector winds. SeaWinds on QuikSCAT data has been found to be highly accurate in nonraining, moderate wind speed areas [Bentamy et al., 2000; Draper and Long, 2002]. However, the quality of SeaWinds on QuikSCAT retrieved winds is degraded by rain contamination, especially in storm regions [Jelenak et al., 2002; Portabella and Stoffelen, 2001]. Globally, rain is estimated to affect between $4 \%$ and $10 \%$ of SeaWinds data. Although rain flagging techniques have been developed [Huddleston and Stiles, 2000; Mears et al., 2000], the current wind retrieval method does not incorporate rain effects. As a result, rain attenuation and backscatter are interpreted as wind-induced features [Weissman et al., 2002].

[3] In a rain-free environment, scatterometer wind retrieval is possible due to scattering from wind-generated gravitycapillary waves [Ulaby et al., 1981]. The normalized radar backscattering cross-section $\left(\sigma^{\circ}\right)$ is a function of the size and orientation of the waves and thus a function of the wind. The relationship between $\sigma^{\circ}$ and the wind is known as the

Copyright 2004 by the American Geophysical Union. 0148-0227/04/2002JC001741\$09.00
Geophysical Model Function (GMF) [Freilich and Dunbar, 1993; Wentz et al., 1998; Wentz and Smith, 1999]. The wind is inferred by inverting the GMF, given several $\sigma^{\circ}$ measurements at different azimuth angles.

[4] Rain corrupts the wind retrieval process by altering the wind-induced radar backscatter signature. Rain striking the water creates rings, stalks, and crowns from which the signal scatters [Bliven et al., 1997]. Rain also alters the windinduced capillary wave field, suppressing the wind/backscatter directional dependence [Bliven et al., 1989], which may limit wind estimation in cases of wide-spread rain [Contreras et al., 2003]. The scatterometer signal is additionally scattered and attenuated by falling hydrometeors.

[5] In this paper, we use a simple phenomenological backscatter model to characterize the effects of rain on SeaWinds on QuikSCAT backscatter. We assume that all rain effects are isotropic, allowing us to model the backscatter as a function of integrated rain rate and effective nonraining $\sigma^{\circ}$ in closed form. For comparison to rain-free backscatter conditions, the effective nonraining $\sigma^{\circ}$ from wind is estimated using numerical weather prediction (NWP) winds from the National Centers for Environmental Prediction (NCEP) projected through the GMF. In order to estimate the rain-induced parameters of the model, we use 100 co-located regions of Precipitation Radar (PR) data from the Tropical Rainfall Measuring Mission (TRMM) 
satellite and SeaWinds on QuikSCAT data. Each co-located region contains the portion of the overlapping swaths in which the TRMM PR time tags are within \pm 10 minutes of the corresponding QuikSCAT time tags. The co-location set spans a 3-month period from August to October 1999. We use only the co-located regions where the overlapping TRMM PR swath contains more than $2.5 \%$ measurements flagged as "rain certain" in the TRMM $2 \mathrm{~A} 25$ files, eliminating rain free areas from the analysis. The co-located set is limited to the tropics within $\pm 37^{\circ}$ of the equator, where rain contamination is the most frequent. While we use data from TRMM PR, previous analyses of the effects of rain on Ku-band backscatter have used data collected from ship [Contreras et al., 2003], buoy [Weissman et al., 2002], and radiometer [Stiles and Yueh, 2002] observations.

[6] In section 2, the SeaWinds and TRMM PR instruments are described. In section 3 , the wind/rain backscatter model is developed and the parameters of the model are estimated. In section 4, an analysis of the surface perturbation due to rain is presented along with validation of the backscatter model as a function of rain rate and surface $\sigma^{\circ}$ from wind. Conclusions are given in section 5. We demonstrate that the surface backscatter from rain dominates the rain-induced signal for low to moderate rain rates while atmospheric scattering dominates at high rain rates. Overall, the simple backscatter model estimates $94 \%$ of the colocated SeaWinds on QuikSCAT backscatter values to within $3 \mathrm{~dB}$ and corresponds well with a nonparametric estimate of the measured $\sigma^{\circ}$ as a function of rain rate and effective nonraining wind $\sigma^{\circ}$. Using the simple backscatter model, the conditions are determined for which estimation of rain from SeaWinds measurements is possible, and for which wind retrieval is not possible.

\section{Data}

[7] Here, we describe each data source used in our analysis, including the SeaWinds on QuikSCAT scatterometer, NCEP NWP winds, and the TRMM PR.

[8] The SeaWinds on QuikSCAT scatterometer is the first scanning pencil-beam instrument designed to measure marine winds. The Ku-band SeaWinds instrument collects $\sigma^{\circ}$ measurements of the ocean surface at $13.4 \mathrm{GHz}$. The QuikSCAT satellite revolves in a near-polar orbit and covers over $90 \%$ of the earth daily. Once $\sigma^{\circ}$ values are measured, wind estimation is performed by inverting the GMF, given multiple $\sigma^{\circ}$ measurements at different azimuth angles for each wind vector cell [Chi and $L i, 1988$ ]. The multiple azimuthal looks are necessary to help resolve directional ambiguity in the wind vector estimate. To allow sufficient azimuthal diversity, the SeaWinds design uses fore and aft observations from two rotating antenna beams. The outer (v-pol) beam operates at $54^{\circ}$ incidence and has a $3 \mathrm{~dB}$ footprint of $37 \times 52 \mathrm{~km}$. The inner (h-pol) beam operates at $46^{\circ}$ incidence and has a $3 \mathrm{~dB}$ footprint of $34 \times 44 \mathrm{~km}$ [Spencer et al., 1997]. Because the h- and v-pol measurements have different characteristics, it is necessary to analyze them separately.

[9] The wind estimation process produces several possible solutions at each wind vector cell, requiring "nudging" from an outside estimate of the wind to produce a unique vector field [Stiles et al., 2002]. These nudging winds are obtained from NCEP $1000 \mathrm{mb}$ winds, included in the QuikSCAT level 2B (L2B) data files. They provide an estimate of the nonraining wind used in our analysis. The NCEP winds are trilinearly interpolated (in space and time) from a $2.5^{\circ} \times$ $2.5^{\circ}$ latitude-longitude grid with a temporal resolution of 6 hours [Wentz and Smith, 1999] to the QuikSCAT wind vector cell locations. It is commonly known that the $1000 \mathrm{mb}$ NCEP wind speeds are generally $10 \%-20 \%$ higher than the $10 \mathrm{~m}$ neutral stability winds measured by SeaWinds. This, along with prediction and interpolation errors, introduces a region-dependent bias in the SeaWinds-NCEP comparison data. To ameliorate these effects, a bias correction for NCEP is presented in section 3.1. Overall, the RMS differences between SeaWinds on QuikSCAT and NWP analysis fields are $\sim 1.4 \mathrm{~m} / \mathrm{s}$ for speeds from $3-20 \mathrm{~m} / \mathrm{s}$ and 14 degrees for speeds from $5-20 \mathrm{~m} / \mathrm{s}$ (http://podaac.jpl.nasa.gov/quikscat/ qs-rlsadd.doc).

[10] TRMM PR data is used to evaluate the effect of rain on SeaWinds h- and v-pol backscatter measurements. The TRMM satellite has been in operation since 1997 and orbits at a low inclination angle of $35^{\circ}$, providing coverage of the tropics. The PR instrument has a much higher resolution $(\sim 4 \times 4 \mathrm{~km})$ than SeaWinds and is electronically scanned within $17^{\circ}$ of nadir [Kozu et al., 2001]. Since the radar is near-nadir looking, the PR swath width at $200 \mathrm{~km}$ is much narrower than SeaWinds' $1800 \mathrm{~km}$ swath. Figure $1 \mathrm{com}-$ pares the swath geometry of the TRMM PR and SeaWinds instruments. Although the viewing geometries of TRMM and SeaWinds are quite different, both instruments operate at approximately the same Ku-band frequency $(13.8 \mathrm{Ghz}$ for TRMM PR versus $13.4 \mathrm{GHz}$ for SeaWinds). Thus the atmospheric effects of rain on the SeaWinds scatterometer and TRMM PR are similar. Standard PR data products used here include unadjusted reflectivity in 3 spatial dimensions $\left(Z_{m}\right)$ from the level $1 C 21$ data files, level 2A25 integrated rain rate $(R)$, and level $2 \mathrm{~A} 25$ path integrated attenuation (PIA) [Iguchi et al., 2000].

\section{Modeling $\sigma^{\circ}$ in Rain and Wind}

[11] This section presents a simple backscatter model and estimates the model parameters using the co-located data sources. As previously noted, rain striking the surface perturbs the wind-wave field and causes additional scattering from rain-induced surface features. Along with surface effects, rain in the atmosphere also attenuates and scatters the scatterometer signal. The scattering and attenuation parameters can be combined into a simple phenomenological model,

$$
\sigma_{m}=\left(\sigma_{w}+\sigma_{s r}\right) \alpha_{r}+\sigma_{r}
$$

where $\sigma_{m}$ is the measured SeaWinds backscatter, $\sigma_{w}$ is the wind-induced radar backscatter, $\sigma_{s r}$ is the surface backscatter perturbation due to rain striking the water, $\alpha_{r}$ is the two-way atmospheric rain attenuation, and $\sigma_{r}$ is volume scattering due to falling raindroplets.

[12] Equation (1) combines all surface rain effects into one additive perturbation parameter $\sigma_{s r}$ Although this relationship for the surface backscatter does not fully represent the complicated nature of surface scattering from wind- and raininduced ocean waves, we are interested only in the average 


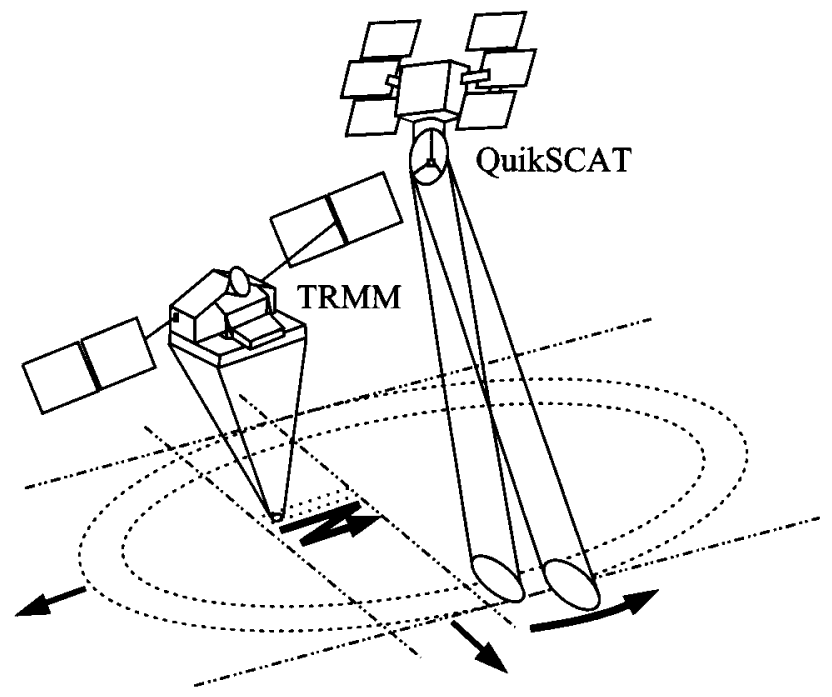

Figure 1. Swath geometry of the TRMM PR and SeaWinds on QuikSCAT instruments.

change in SeaWinds surface $\sigma^{\circ}$ due to rain. Thus an additive relationship is sufficient for our first-order analysis.

[13] The model of equation (1) is used to compare the surface perturbation to the atmospheric backscatter in section 4.1. However, in the final analysis, we are only interested in the bulk augmentation of the scatterometer signal due to rain. Thus the model is further simplified in section 4.2 by summing the attenuated surface perturbation and the atmospheric scattering terms, creating a single effective rain backscatter parameter $\sigma_{e}$. The combined rain effect model is

$$
\sigma_{m}=\sigma_{w} \alpha_{r}+\sigma_{e}
$$

where $\sigma_{e}=\sigma_{s r} \alpha_{r}+\sigma_{r}$ This simplification is also used in Stiles and Yueh [2002].

\subsection{Determining Model Parameters From TRMM and NCEP}

[14] We calculate the parameters from equation (1) by synergistically combining co-located data from the TRMM PR and NWP fields to estimate the SeaWinds-observed backscatter and attenuation from rain, and the effective nonraining backscatter from wind. Because TRMM PR is higher resolution than SeaWinds, comparison of the two datasets requires averaging of the TRMM parameters over the SeaWinds footprint to account for the aperture of the SeaWinds antenna. In order to make the notation tractable, when needed, we prime $\left({ }^{\prime}\right)$ parameters that have the resolution of the PR and remove the prime after averaging over the SeaWinds footprint. Also, parentheses in the subscripts of symbols are used to indicate the source of the data used to estimate that parameter.

[15] The SeaWinds on QuikSCAT measured backscatter $\sigma_{m(Q S C A T)}$ is taken from the QuikSCAT L1B data set and corrected for atmospheric (nonrain) attenuation using the QuikSCAT L2A attenuation map. These data were obtained from the NASA Physical Oceanography Distributed Active Archive Center at the Jet Propulsion Laboratory/California Institute of Technology.
[16] In evaluating the effect of rain on SeaWinds, the effective vertically-integrated rain rate observed by SeaWinds is estimated from the TRMM 2A25 integrated rain rate. The PR rain rate $R_{(P R)}^{\prime}$ is averaged over the SeaWinds footprint, weighting each data point by the SeaWinds antenna gain pattern,

$$
R_{(P R)}=\frac{\sum_{i=1}^{N} G_{i} R_{i(P R)}^{\prime}}{\sum_{i=1}^{N} G_{i}}
$$

where $G_{i}$ is the SeaWinds two-way antenna gain pattern at the ith PR measurement, $N$ is the number of PR data points within a 6-dB antenna pattern contour, and $R_{i(P R)}^{\prime}$ is the PRobserved rain rate. We note that the PR-derived rain rate estimate is integrated (essentially) normal to the surface, and thus does not take into account the slant range of the SeaWinds instrument.

[17] The antenna-weighted rain rate differs somewhat from an unweighted average due to the spatial variability of the rain within the antenna footprint. This "beam-filling" variability is examined by evaluating the error between the average rain rate weighted by the antenna beam pattern and the unweighted average rain for individual measurements. Using the QuikSCAT/TRMM PR co-located data set, both antenna-weighted $\left(R_{(P R)}\right)$ and unweighted $\left(R_{u}\right)$ rain rate estimates for each SeaWinds measurement are computed from the PR-derived integrated rain rates. The unweighted rain rates are the average of the PR integrated rain rates within the 6-dB SeaWinds footprint,

$$
R_{u}=\frac{1}{N} \sum_{i=1}^{N} R_{i(P R)}^{\prime}
$$

The statistics of the normalized error between the antennaweighted and unweighted measurements with significant unweighted rain rates $(>2 \mathrm{~km} \mathrm{~mm} / \mathrm{hr})$ are calculated for the entire co-located data set. The normalized error is defined as the error divided by the unweighted measurements, i.e., $\left(R_{(P R)}-R_{u}\right) / R_{u}$. The mean normalized error is -0.0072 (negligible), while the standard deviation is 0.21 , suggesting that while the beamfilling effect introduces variability into the rain rate estimates, it does not shift the mean. A histogram of the PR-derived antenna-averaged rain rates $R_{(P R)}$ for SeaWinds over the co-located data set is shown in Figure 2. The co-located data set allows evaluation of rain effects for rain rates up to about $100 \mathrm{~km} \mathrm{~mm} / \mathrm{hr}$.

[18] The effective nonraining wind backscatter $\sigma_{w}$ is computed from co-located NWP estimates of the wind from NCEP included in the QuikSCAT level 2B data files. As previously noted, these wind fields are interpolated in time and space to the same grid as the SeaWinds $25 \times 25 \mathrm{~km}$ wind product. For each SeaWinds observation, we further interpolate the NCEP wind data to the center of each SeaWinds $\sigma^{\circ}$ measurement using cubic spline interpolation of the zonal and meridianal components of the wind. The process is not particularly sensitive to the interpolation method since the NCEP winds are low resolution. Each NCEP wind vector is then projected through the GMF to yield an estimate of the nonraining wind backscatter,

$$
\sigma_{w(N C E P)}=\mathcal{M}\left(u_{(N C E P)}, \chi_{(N C E P)}, \theta, \text { pol }\right)
$$




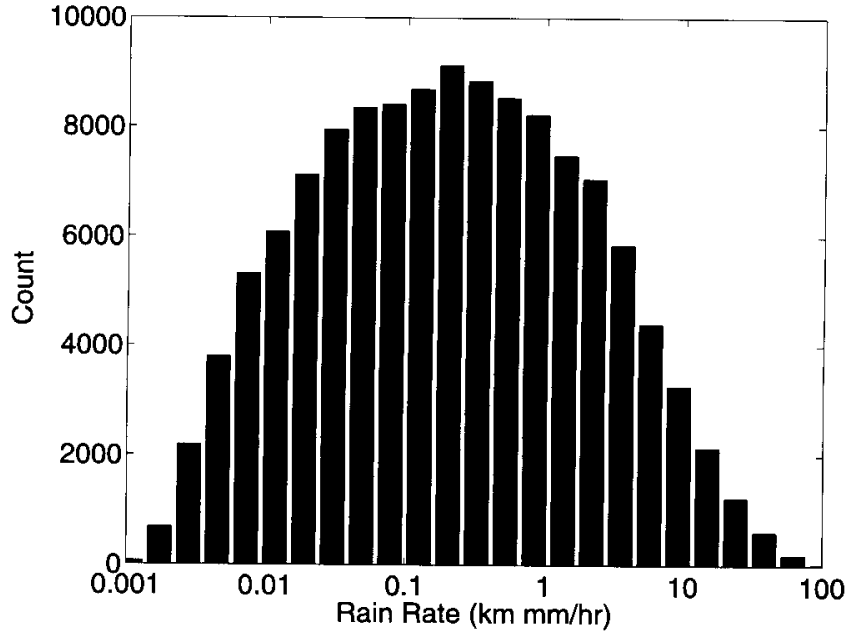

Figure 2. Histogram of SeaWinds antenna-weighted rain rates derived from TRMM PR data $R_{(P R)}$ for the co-located data set.

where $u_{(N C E P)}$ is the NCEP model wind speed, $\chi_{(N C E P)}$ is the relative azimuth angle of the NCEP wind direction, $\theta$ is the incidence angle and pol is the polarization of the SeaWinds measurement.

[19] As mentioned earlier, the wind backscatter estimate from NCEP has some bias due to prediction errors, errors in the GMF, and differences in reference height between the $10 \mathrm{~m}$ SeaWinds wind product and $1000 \mathrm{mb}$ NCEP winds. Because NCEP is low resolution, we assume that the bias error is spatially correlated. For each SeaWinds backscatter measurement, we estimate the bias error $\epsilon$ as a Gaussianweighted average of the error between SeaWinds and NCEP $\sigma^{\circ}$ values for surrounding measurement cells in the same look direction (i.e., fore/aft) with very little or no rain. For the $j$ th measurement,

$$
\epsilon^{j}=\sum_{i} W^{i j}\left(\sigma_{m(Q S C A T)}^{i}-\sigma_{w(N C E P)}^{i}\right) / \sum_{i} W^{i j}
$$

where $i$ sums over all measurements in the same look direction with rain rate less than $0.05 \mathrm{~km} \mathrm{~mm} / \mathrm{hr}$ as determined by TRMM PR. The threshold of $0.05 \mathrm{~km} \mathrm{~mm} / \mathrm{hr}$ is chosen because it is approximately the rain rate achieved for a SeaWinds footprint when only one co-located PR cell contains a rain rate of $0.7 \mathrm{~km} \mathrm{~mm} / \mathrm{hr}$. The value of $0.7 \mathrm{~km} \mathrm{~mm} / \mathrm{hr}$ is the lower bound of the sensitivity of the TRMM PR for a rain height of $1 \mathrm{~km}$ [Kozu et al., 2001]. The weighting $W^{i j}$ is calculated by

$$
W^{i j}=\exp \left(\frac{1}{2} \frac{d(i, j)^{2}}{20^{2}}\right)
$$

where $d(i, j)$ is the euclidean distance between the $i t h$ and $j t h$ measurements in $\mathrm{km}$. The distance scale of $20 \mathrm{~km}$ (yielding an effective 3- $\sigma$ diameter of $120 \mathrm{~km}$ ) is subjectively chosen; however, because the NCEP wind are low resolution, the bias estimate is not particularly sensitive to this value. Our estimate of $\sigma_{w}$ is now written as the NCEP-determined value plus the bias error,

$$
\sigma_{w}=\sigma_{w(N C E P)}+\epsilon .
$$

The mean $\epsilon$ over the QuikSCAT/TRMM PR data set is $\sim-0.0025$ while the standard deviation is $\sim 0.0064$, suggesting that NCEP predicted wind backscatter is biased slightly high, as expected.

[20] The estimate of the NCEP-SeaWinds $\sigma^{\circ}$ bias error is most accurate when there are no fine-scale wind features in the near vicinity of the SeaWinds measurement. Because fine-scale features may be misplaced or absent in the lowresolution NCEP data, the estimate of $\sigma_{w}$ error is expected to be less reliable in such areas. Also, in regions of widespread rain, the estimate is less reliable because there are fewer no-rain measurements in the vicinity from which to make the bias estimate.

[21] The two-way atmospheric attenuation factor $\alpha_{r}$ of equation (1) is calculated from the PIA estimates in the TRMM 2A25 data sets. First, the PIA measurements are adjusted for the PR slant range and converted to normal space,

$$
\alpha_{r(P R)}^{\prime}=10^{-\cos \theta_{(P R)} \operatorname{PIA}(2 \mathrm{AA} 25) / 10} .
$$

Values for $\alpha_{r(P R)}^{\prime}$ where there is no rain detected are set to one. For each SeaWinds observation, the co-located values of $\alpha_{r(P R)}^{\prime}$ are weighted-averaged over the 6dB SeaWinds footprint to yield the effective SeaWinds on QuikSCAT columnar path integrated attenuation, and then scaled by the secant of the SeaWinds incidence angle $\theta_{(Q S C A T)}$ to adjust for the SeaWinds slant range,

$$
\mathrm{PIA}=-\sec \theta_{(Q S C A T)} 10 \log _{10}\left(\frac{\sum_{i=1}^{N} G_{i} \alpha_{r i(P R)}^{\prime}}{\sum_{i=1}^{N} G_{i}}\right)
$$

where $\alpha_{r i(P R)}^{\prime}$ is the $i t h$ PIA value. The attenuation parameter is then converted to normal space,

$$
\alpha_{r(P R)}=10^{-\mathrm{PIA} / 10}
$$

[22] Estimates for the volume-scattering cross-section $\left(\sigma_{r}\right)$ are calculated from measured reflectivities $\left(Z_{m}\right)$ obtained from the TRMM $1 \mathrm{C} 21$ data set. The actual (attenuation-adjusted) reflectivity of the atmospheric rain $\left(Z_{e}\right)$ is related to the measured reflectivity through the equation,

$$
Z_{m}(r)=Z_{e}(r) \alpha_{r}(r) \mathrm{mm}^{6} \mathrm{~m}^{-3}
$$

where $r$ is the range, and $\alpha_{r}(r)$ is the path integrated twoway attenuation at range $r$. The volume backscattering coefficient can be found from Ulaby et al. [1981],

$$
\sigma_{v r}(r)=10^{-10} \frac{\pi^{5}}{\lambda_{0}^{4}}\left|K_{w}\right|^{2} Z_{e}(r) \mathrm{m}^{2} / \mathrm{m}^{3}
$$

where $\lambda(\mathrm{cm})$ is the electromagnetic wavelength of SeaWinds, and $\left|K_{w}\right|^{2}$ is a coefficient related to the absorption properties of water (assumed to be 0.9). The quantity $\sigma_{v r}$ is radar backscatter cross-section per unit volume. 
[23] The volume backscattering cross-section observed by the satellite $\left(\sigma_{v r o}\right)$ is attenuated by the two-way attenuation factor, $\alpha_{r}(r)$ and is equal to,

$$
\begin{aligned}
\sigma_{v r o}(r) & =\sigma_{v r}(r) \alpha_{r}(r) \\
& =10^{-10} \frac{\pi^{5}}{\lambda_{0}^{4}}\left|K_{w}\right|^{2} Z_{e}(r) \alpha_{r}(r) \\
& =10^{-10} \frac{\pi^{5}}{\lambda_{0}^{4}}\left|K_{w}\right|^{2} Z_{m}(r) .
\end{aligned}
$$

The total atmospheric rain backscatter as seen by the PR $\left(\sigma_{r(P R)}^{\prime}\right)$ is $\sigma_{v r o}$ integrated through the PR antenna beam to the lowest no-surface-clutter range $\left(r_{n c}\right)$,

$$
\begin{aligned}
\sigma_{r(P R)}^{\prime} & =\int_{0}^{r_{n c}} \sigma_{v r o}(s) d s \mathrm{~m}^{2} / \mathrm{m}^{2} \\
& \approx \sum_{s=1}^{N_{m c}} \sigma_{v r o}(s) \Delta r \mathrm{~m}^{2} / \mathrm{m}^{2}
\end{aligned}
$$

where $\Delta r$ is the vertical range resolution of the PR and $N_{n c}$ is the lowest no-surface-clutter range bin. All valid $\sigma_{r(P R)}^{\prime}$ values are weighted-averaged over the SeaWinds footprint,

$$
\sigma_{r(P R)}=\frac{\sum_{i=1}^{N} G_{i} \sigma_{r i(P R)}^{\prime}}{\sum_{i=1}^{N} G_{i}}
$$

where $\sigma_{r i(P R)}^{\prime}$ is the ith PR rain backscatter value. Values for $\sigma_{r(P R)}^{\prime}$ where there is no rain detected are set to zero.

[24] Thus far we have derived estimates for the atmospheric scattering and attenuation from rain as seen by SeaWinds on QuikSCAT. We have assumed that the PRderived atmospheric backscatter $\sigma_{r}$ can be directly applied to SeaWinds. However, because SeaWinds has a longer slant range and a different incidence angle, we expect some error in our estimate of $\sigma_{r}$ The TRMM PR and SeaWinds measurements are only co-located at the ocean surface. For increasing height, the TRMM PR and SeaWinds beams become misaligned. Temporal changes in rain profiles between the TRMM and SeaWinds observation times introduce additional errors. Also, we expect a lower sensitivity at v-pol than h-pol [Stiles and Yueh, 2002]. We do not attempt to model all the sources of error in $\sigma_{r}$ Rather, we evaluate the sensitivity of the overall model to the PRderived estimate of $\sigma_{r}$ in section 4.1.

\subsection{Relating PR Atmospheric Parameters to Rain Rate}

[25] Here, we relate the PR-derived atmospheric parameters $\alpha_{r(P R)}$ and $\sigma_{r(P R)}$ to the integrated rain rate. Power law (linear $\log -\log$ ) models are widely used to relate rain rate $R$ to the rain extinction coefficient $\kappa_{e r}$ and reflectivity $Z_{e}$, from which $\alpha_{r}$ and $\sigma_{r}$ are derived [Ulaby et al., 1981; Iguchi et $a l ., 2000]$. The energy transfer equations relate $\kappa_{e r}$ and $Z_{e}$ to $\alpha_{r}$ and $\sigma_{r}$ by

$$
\mathrm{PIA}=-10 \log _{10}\left(\alpha_{r}\right)=2 \int_{0}^{r_{n c}} \kappa_{e r}(r) d r
$$

and

$$
\sigma_{r}=C \int_{0}^{r_{n c}} Z_{e}(r) 10^{-\left(2 \int_{0}^{r} \kappa_{\text {err }}\left(r^{r}\right) d r\right) / 10} d r
$$

where $C=10^{-10} \pi^{5} \lambda_{0}{ }^{-4}\left|K_{w}\right|^{2}$. Although we are not directly interested in $\kappa_{e r}$ and $Z_{e}$, the linear nature of equation (17) suggests that a linear log-log model may suffice for estimating PIA. However, the nonlinear attenuation term of equation (18) may cause $\sigma_{r}$ to somewhat deviate from a power law model. Owing to this nonlinearity in equation (18) and the fact that we do not include information about rain profile or type, we model the PR-derived atmospheric parameters with both linear and quadratic $\log -\log$ fits, i.e.,

$$
\begin{aligned}
& 10 \log _{10}(\mathrm{PIA}) \approx f_{a}\left(R_{d B}\right)=\sum_{n=0}^{N} x_{a}(n) R_{d B}^{n} \\
& 10 \log _{10}\left(\sigma_{r}\right) \approx f_{r}\left(R_{d B}\right)=\sum_{n=0}^{N} x_{r}(n) R_{d B}^{n}
\end{aligned}
$$

where $R_{d B}=10 \log _{10}(R)$, and $\mathrm{N}$ is one for the linear model and two for the quadratic model.

[26] The values for $\alpha_{r}$ and $\sigma_{r}$ can be cast into matrix equations of the form

$$
\mathbf{P I A}=\mathbf{R} \mathbf{x}_{\mathbf{a}}
$$

$$
\overrightarrow{\boldsymbol{\sigma}}_{r}=\mathbf{R x}_{\mathbf{r}}
$$

where

$$
\mathbf{R}=\left[\begin{array}{ll}
\mathbf{1} & \mathbf{r}
\end{array}\right]
$$

for the linear log-log model and

$$
\mathbf{R}=\left[\begin{array}{lll}
1 & \mathbf{r} & \mathbf{r}^{2}
\end{array}\right]
$$

for the quadratic log-log model. In equation (21), the elements of PIA are equal to $10 \log _{10}$ PIA where PIA is related to $\alpha_{r}$ by equation (17). In equation (22), $\vec{\sigma}_{r}$ is a vector containing $\sigma_{r}$ values in decibels. In Equations (23) and (24), $\mathbf{r}$ is a vector containing rain rate in decibels $\left(R_{d B}\right)$. The estimation of $\mathbf{x}_{\mathbf{a}}$ and $\mathbf{x}_{\mathbf{r}}$ is performed by first making a nonparametric (moving average) estimate of $10 \log _{10}$ PIA and $10 \log _{10} \sigma_{r(P R)}$ as a function of rain rate at regular logarithmically spaced rain rate bins. In doing this, we use an Epanechnikov kernel [Wand and Jones, 1995] with a support of $3 \mathrm{~dB}$ in rain rate. The parameters $\mathbf{x}_{\mathbf{a}}$ and $\mathbf{x}_{\mathbf{r}}$ are solved for using linear least squares,

$$
\begin{gathered}
\mathbf{x}_{\mathbf{q}}=\mathbf{R}^{\dagger} \mathbf{P I A} \\
\mathbf{x}_{\mathbf{r}}=\mathbf{R}^{\dagger} \overrightarrow{\boldsymbol{\sigma}}_{\mathbf{r}}
\end{gathered}
$$

where PIA and $\vec{\sigma}_{\mathbf{r}}$ contain the nonparametric estimated values and $\mathbf{R}^{\dagger}$ is the least squares pseudo-inverse of $\mathbf{R}$ which is formed using the rain rate bins. The estimated parameters are given in Table 1.

\section{Analysis}

[27] Thus far, all rain-induced parameters of equation (1) except the surface perturbation $\sigma_{s r}$ have been estimated. The 
Table 1. Coefficients of the Linear and Quadratic Fits to the Parameters PIA and $\sigma_{r(P R)}$

\begin{tabular}{lccccc}
\hline & \multicolumn{2}{c}{ h-pol } & & \multicolumn{2}{c}{ v-pol } \\
\cline { 2 - 3 } \cline { 5 - 6 } & Linear & Quadratic & & Linear & Quadratic \\
\hline$x_{a}(1)$ & -11.90 & -11.55 & & -11.21 & -10.78 \\
$x_{a}(2)$ & 1.01 & 1.00 & & 1.01 & 1.00 \\
$x_{a}(3)$ & - & -0.0017 & & - & -0.0021 \\
$x_{r}(1)$ & -35.34 & -34.90 & -35.32 & -34.85 \\
$x_{r}(2)$ & 1.03 & 1.07 & & 1.03 & 1.08 \\
$x_{r}(3)$ & - & -0.0053 & & - & -00057 \\
\hline
\end{tabular}

surface rain perturbation is often ignored by theoretical models due to a lack of understanding of its effects. However, it is important to include the surface perturbation to afford the best modeling of rain. This can be done directly using the wind/rain backscatter model from equation (1), or indirectly using the combined rain effect model of equation (2). In section 4.1, we estimate the surface perturbation directly using the co-located QuikSCAT/ TRMM PR data and compare the effect of the surface perturbation to that of the atmospheric backscatter. In section 4.2 , we apply the combined rain effect model to SeaWinds on QuikSCAT data. Using the combined rain effect model, the conditions for which wind and rain retrieval are possible from scatterometer data is given in section 4.3 .

\subsection{Comparing the Surface Perturbation to the Atmospheric Backscatter}

[28] This section estimates the surface perturbation and presents a qualitative comparison of the effect of the surface perturbation to the atmospheric rain backscatter. Surface backscatter from rain striking the water has been studied at low incidence angles $\left(30^{\circ}\right)$ in wave-tank data [Bliven and Giovanangeli, 1993; Craeye et al., 1997], and at higher incidence angles $\left(31^{\circ}, 41^{\circ}, 51^{\circ}, 76^{\circ}\right)$ from ship observations [Contreras et al., 2003], but not at SeaWinds' specific geometries. The QuikSCAT/TRMM PR co-located data affords us the ability to evaluate the contribution of the surface rain perturbation to the total rain backscatter. An estimate of the surface perturbation is obtained by solving equation (1) for $\sigma_{s r}$ and adding appropriate subscripts,

$$
\sigma_{s r}=\alpha_{r(P R)}^{-1}\left(\sigma_{m(Q S C A T)}-\sigma_{r(P R)}\right)-\left(\sigma_{w(N C E P)}+\epsilon\right) .
$$

[29] In comparing the estimated surface perturbation to the atmospheric backscatter, we recognize that error in the PR-derived estimates of the atmospheric rain backscatter $\sigma_{r(P R)}$ arises from differences in slant range, polarization, and calibration between the PR and SeaWinds and introduces a bias into the estimate of $\sigma_{s r}$ To evaluate the sensitivity of $\sigma_{s r}$ to the error, we adopt a variable calibration parameter $\gamma$ that is multiplied by $\sigma_{r(P R)}$. The modified estimate for $\sigma_{s r}$ is

$$
\sigma_{s r}(\gamma)=\alpha_{r(P R)}^{-1}\left(\sigma_{m(Q S C A T)}-\gamma \sigma_{r(P R)}\right)-\left(\sigma_{w(N C E P)}+\epsilon\right)
$$

[30] As with the PR-derived atmospheric parameters, we write the "calibrated" surface perturbation $\sigma_{s r}(\gamma)$ as a linear and quadratic function of rain rate in log-log space, and solve
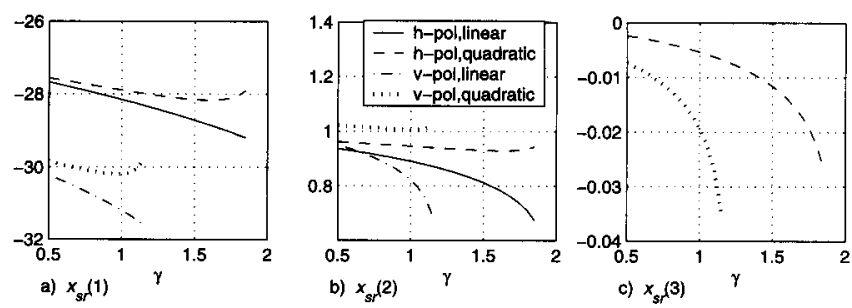

Figure 3. Each parameter of $\mathbf{x}_{\mathbf{s r}}$ as a function of the rain backscatter calibration parameter $\gamma$ for both h-pol and $\mathrm{v}$-pol observations and both linear and quadratic fits.

for it using a similar method as described in section 3.2 for varying $\gamma$. The model for $\sigma_{s r}$ is written as

$$
10 \log _{10}\left(\sigma_{s r}(\gamma)\right) \approx f_{s r}^{\gamma}\left(R_{d B}\right)=\sum_{n=0}^{N} x_{s r}^{\gamma}(n) R_{d B}^{n}
$$

Because the estimate of the surface perturbation $\sigma_{s r}(\gamma)$ can be negative, the nonparametric estimate described in section 3.2 is performed in normal-space for $\sigma_{s r}(\gamma)$. The nonparametric estimate is then converted to decibels and a least squares estimate of $\sigma_{s r}(\gamma)$ is formed for a range of $\gamma$ values.

[31] The estimated parameters of $\sigma_{s r}(\gamma)$ are plotted as a function of the calibration parameter $\gamma$ in Figure 3 for both linear and quadratic fits. As a note, the estimates are only valid for v-pol observations up to $\gamma=1.15$ and h-pol observations up to $\gamma=1.85$. At a larger $\gamma$, the nonparametric estimate of $\sigma_{s r}$ becomes negative. From Figure $3 \mathrm{a}$, the constant term $x_{s r}^{\gamma}(1)$ is not particularly sensitive to the choice of $\gamma$. The highest order terms, $x_{s r}^{\gamma}(2)$ for the linear model and $x_{s r}^{\gamma}$ (3) for the quadratic model, are the most sensitive, especially as $\gamma$ increases. A method of picking the optimum calibration parameter using a least squares approach is presented in the Appendix. From the analysis, the optimum calibration parameter for h-pol is $\gamma_{\text {opt }}=1.70$. For v-pol, the optimum parameter is $\gamma_{o p t}=0.95$.

[32] A direct comparison of the estimated surface perturbation parameters (Figure 3) to the atmospheric scattering parameters (Table 1) shows that for all $\gamma$, the constant term of the surface perturbation is significantly higher than the

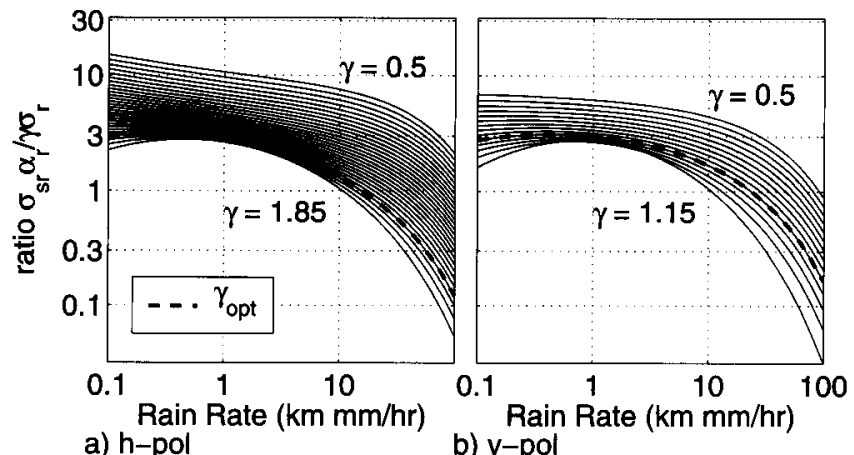

Figure 4. Ratio of the attenuated surface perturbation $\alpha_{r} \sigma_{s r}(\gamma)$ to the calibrated atmospheric rain backscatter $\gamma \sigma_{r}$ for several values of $\gamma$ plotted as a function of rain rate for a) h-pol and b) v-pol. 
Table 2. Estimated Parameters of $\sigma_{e}$ for h-pol and v-pol for Both Linear and Quadratic Fits

\begin{tabular}{lccccc}
\hline & \multicolumn{2}{c}{ h-pol } & & \multicolumn{2}{c}{ v-pol } \\
\cline { 2 - 3 } \cline { 2 - 3 } & Linear & Quadratic & & Linear & Quadratic \\
\hline$x_{e}(1)$ & -27.57 & -27.04 & & -29.86 & -29.09 \\
$x_{e}(2)$ & 0.83 & 0.94 & & 0.86 & 1.00 \\
$x_{e}(3)$ & - & -0.011 & & - & -0.015 \\
\hline
\end{tabular}

constant term of the atmospheric scattering (compare Figure 3a to Table 1 row 4). Also, the linear and quadratic terms of $\sigma_{s r}(\gamma)$ are on the same order of magnitude as the linear and quadratic terms of $\sigma_{r}$. This comparison demonstrates that the surface perturbation is a significant contributer to the observed rain backscatter.

[33] We further compare the contribution of the surface perturbation and the atmospheric backscatter by computing the ratio of the attenuated surface perturbation $\alpha_{r} \sigma_{s r}(\gamma)$ for each $\gamma$ to the calibrated atmospheric rain backscatter $\gamma \sigma_{r}$ as a function of rain rate (see Figure 4). The ratio $\alpha_{r} \sigma_{s r}(\gamma) / \gamma \sigma_{r}$ is greater than one for rain rates less than $10 \mathrm{~km} \mathrm{~mm} / \mathrm{hr}$, suggesting that the surface rain backscatter dominates at low to moderate rain rates. At higher rain rates, the surface signal is suppressed by attenuation and atmospheric scattering dominates. This qualitative analysis suggests that a theoretical model that includes only atmospheric effects is insufficient in representing the full backscatter. In general, backscattering from the surface dominates for low to moderate rain rates. The model estimates for the surface perturbation compare reasonably well to the model fits in Contreras et al. [2003].

\subsection{Combined Rain Effect Model}

[34] The wind/rain backscatter model affords a closedform relationship between ocean backscatter due to wind and rain rate. However, because we do not precisely know the surface perturbation or error in the atmospheric backscatter estimate, we adopt the combined rain effect model of equation (2) to further analyze the effect of rain on SeaWinds scatterometer measurements. Using the colocated data, we calculate estimates for the effective rain backscatter,

$$
\sigma_{e}=\sigma_{m(Q S C A T)}-\left(\sigma_{w(N C E P)}+\epsilon\right) \alpha_{r(P R)},
$$

and use the same estimation technique to calculate $\sigma_{e}$ as a function of rain rate as performed with $\sigma_{s r}$ (see section 4.1). The effective rain backscatter can be written as a function of rain rate,

$$
10 \log _{10}\left(\sigma_{e}\right) \approx f_{e}\left(R_{d B}\right)=\sum_{n=0}^{N} x_{e}(n) R_{d B}^{n}
$$

The optimization is performed and the estimated values for $x_{e}(n)$ for both linear and quadratic fits are given in Table 2 . Graphics demonstrating the model fits are shown in Figure 5. The estimates $\sigma_{e}$ range from -40 to $-15 \mathrm{~dB}$ for the observed rain rates, demonstrating a significant sensitivity of SeaWinds on QuikSCAT data to rain.

[35] Now that the parameters of the wind/rain backscatter models have been estimated, the measured SeaWinds backscatter can be parameterized by the surface backscatter due to wind and rain rate as

$$
\sigma_{m}\left(\sigma_{w}, R\right)=\sigma_{w} \alpha_{r}(R)+\sigma_{e}(R)
$$

for the combined rain effect model and

$$
\sigma_{m}\left(\sigma_{w}, R\right)=\left(\sigma_{w}+\sigma_{s r}(R)\right) \alpha_{r}(R)+\sigma_{r}(R)
$$
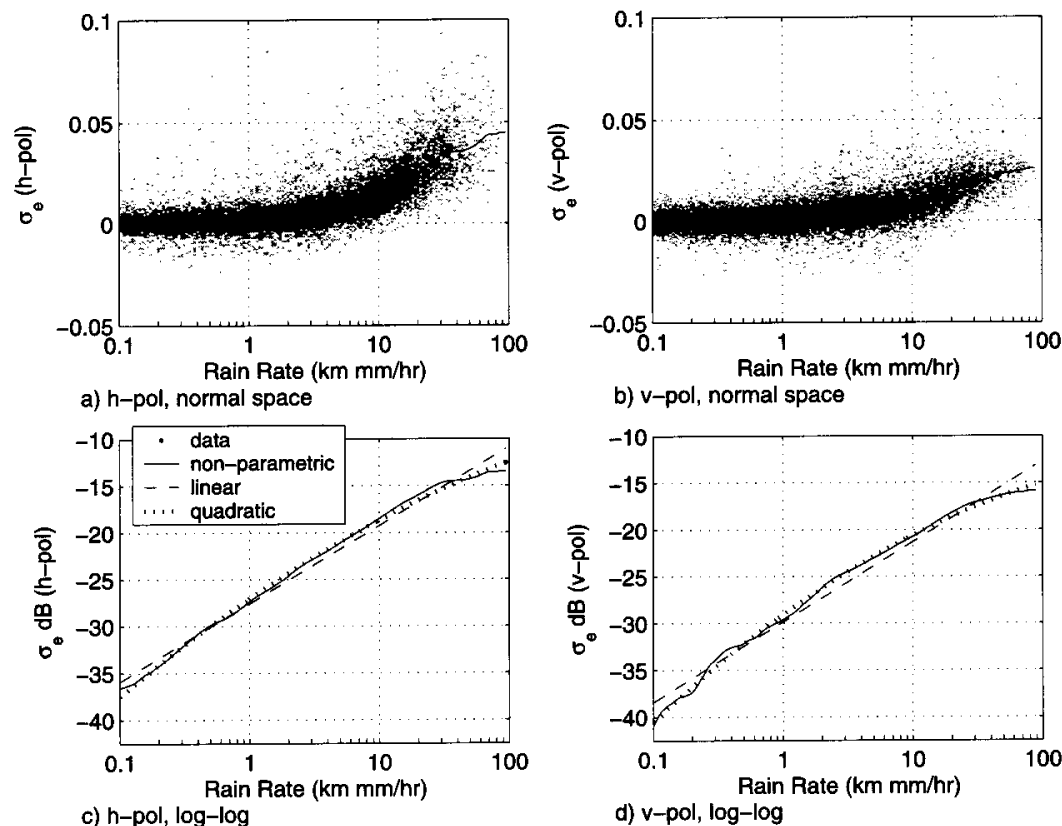

c) $\mathrm{h}-\mathrm{pol}, \log -\log$

d) v-pol, $\log -\log$

Figure 5. Non-parametric and least squares fits to the parameter $\sigma_{e} \cdot(\mathrm{a}, \mathrm{b})$ show the data and nonparametric fit in normal space for h-pol and v-pol. (c, d) show the nonparametric linear and quadratic fits in log-log space. 

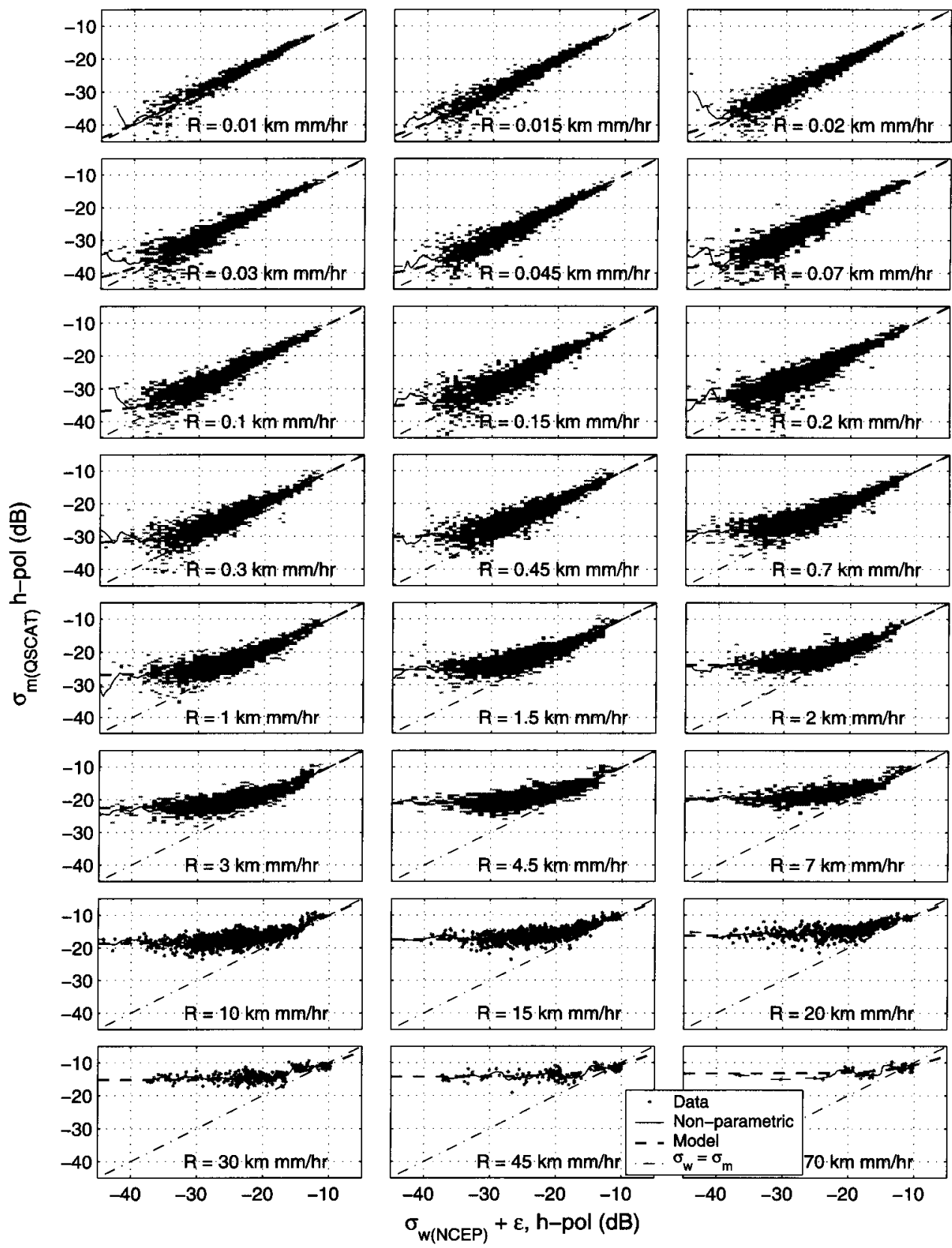

Figure 6. SeaWinds on QuikSCAT measured backscatter $\sigma_{m}$ plotted as a function of effective nonraining wind $\sigma^{\circ}, \sigma_{w}$ for h-pol. Also plotted, a nonparametric estimate and the combined rain effect model.

for the full model. Each rain-induced parameter has a linear or quadratic $\log$-log relationship to rain rate of the form

$$
\begin{gathered}
\sigma_{e}(R)=10^{f_{e}\left(R_{d B}\right) / 10} \\
\sigma_{s r}(R)=10^{f_{s r}^{\gamma}\left(R_{d B}\right) / 10} \\
\alpha_{r}(R)=10^{-10^{f\left(R_{A B}\right) / 10} / 10} \\
\sigma_{r}(R)=\gamma 10^{f_{r}\left(R_{d B}\right) / 10} .
\end{gathered}
$$

Comparing the two models, we find that the full model and the combined rain effect model are very similar. Thus for simplicity, the remaining analysis is applied only to the quadratic combined rain effect model. Similar results follow for the full model.

\subsubsection{Beamfilling: Worst Case Scenario}

[36] Section 3.1 addresses the effect of beamfilling with respect to the averaging procedure. Here, we examine the beamfilling effect with respect to the spatial distribution of the rain. In doing so, we consider a worst case scenario of two measurements where the integrated rain rate, averaged over the SeaWinds footprint, is $0.5 \mathrm{~km} \mathrm{~mm} / \mathrm{hr}$. In the first measurement, the rain rate is $0.5 \mathrm{~km} \mathrm{~mm} / \mathrm{hr}$, uniformly distributed over the measurement area. In the second 

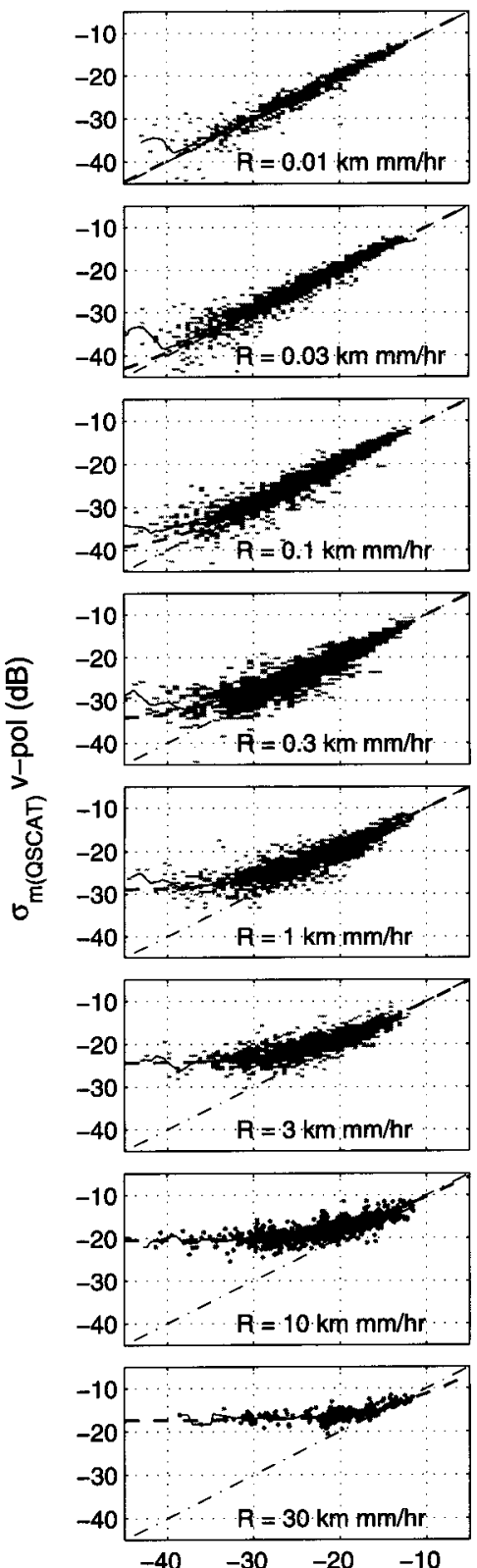
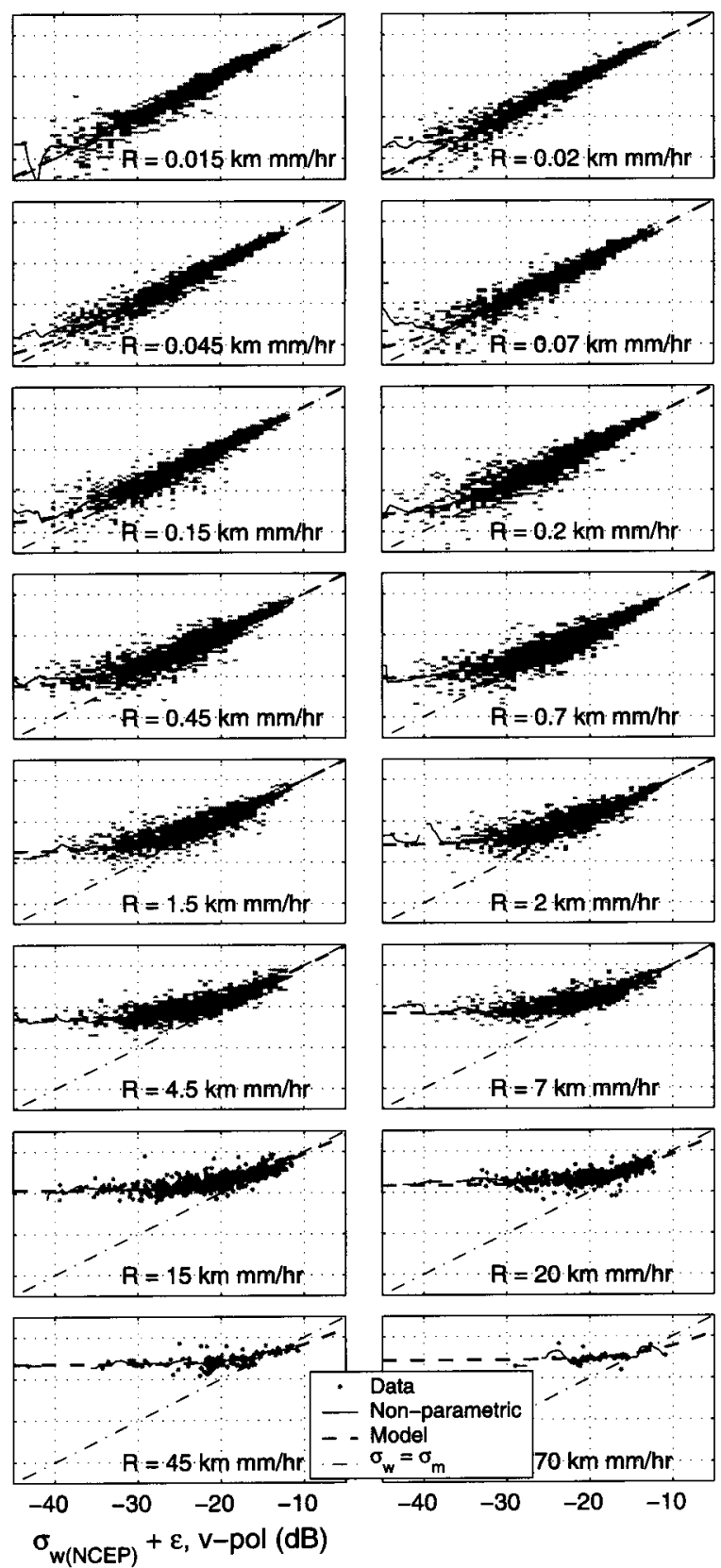

Figure 7. SeaWinds on QuikSCAT measured backscatter $\sigma_{m}$ plotted as a function of effective nonraining wind $\sigma^{\circ}, \sigma_{w}$ for v-pol. Also plotted, a nonparametric estimate and the combined rain effect model.

measurement, the rain rate is $50 \mathrm{~km} \mathrm{~mm} / \mathrm{hr}$, isolated to the area of a single PR measurement cell (with approximately 100 PR cells co-located within the SeaWinds measurement). Using the quadratic combined rain effect model, the effective rain backscatter for the uniform $0.5 \mathrm{~km} \mathrm{~mm} / \mathrm{hr}$ rain rate is $\sigma_{e}=0.001(-30 \mathrm{~dB})$. The effective rain backscatter for the isolated rain event of $R=50 \mathrm{~km} \mathrm{~mm} / \mathrm{hr}$, is $\sigma_{e}=0.039$. Averaging over the SeaWinds footprint yields an effective backscatter of $\sigma_{e}=0.00039(-34 \mathrm{~dB})$. Thus the effect of the uniform rain differs from the worst-case nonuniform rain by about $4 \mathrm{~dB}$. However, the effect of nonuniform beam filling is generally much less substantial. We treat the effect of nonuniform rain as a source of unknown variability in the measurement model, and evaluate the overall accuracy of the model in the following section.

\subsubsection{Model Validation}

[37] Here we compare the combined rain effect model to actual SeaWinds backscatter measurements as a function of $R_{(P R)}$ and $\sigma_{w(N C E P)}+\epsilon$. Figures 6 and 7 show the quadratic combined rain effect model plotted against SeaWinds on QuikSCAT backscatter for h- and v-pol respectively. Visually, the model follows the data very well. In fact, the model is within $3 \mathrm{~dB}$ of the measurements more than $94 \%$ of the time. The standard deviation of the log error is about $1.6 \mathrm{~dB}$ for h-pol and $1.5 \mathrm{~dB}$ for $\mathrm{v}$-pol. The relatively low variance of the model indicates that the simple closed-form model is 

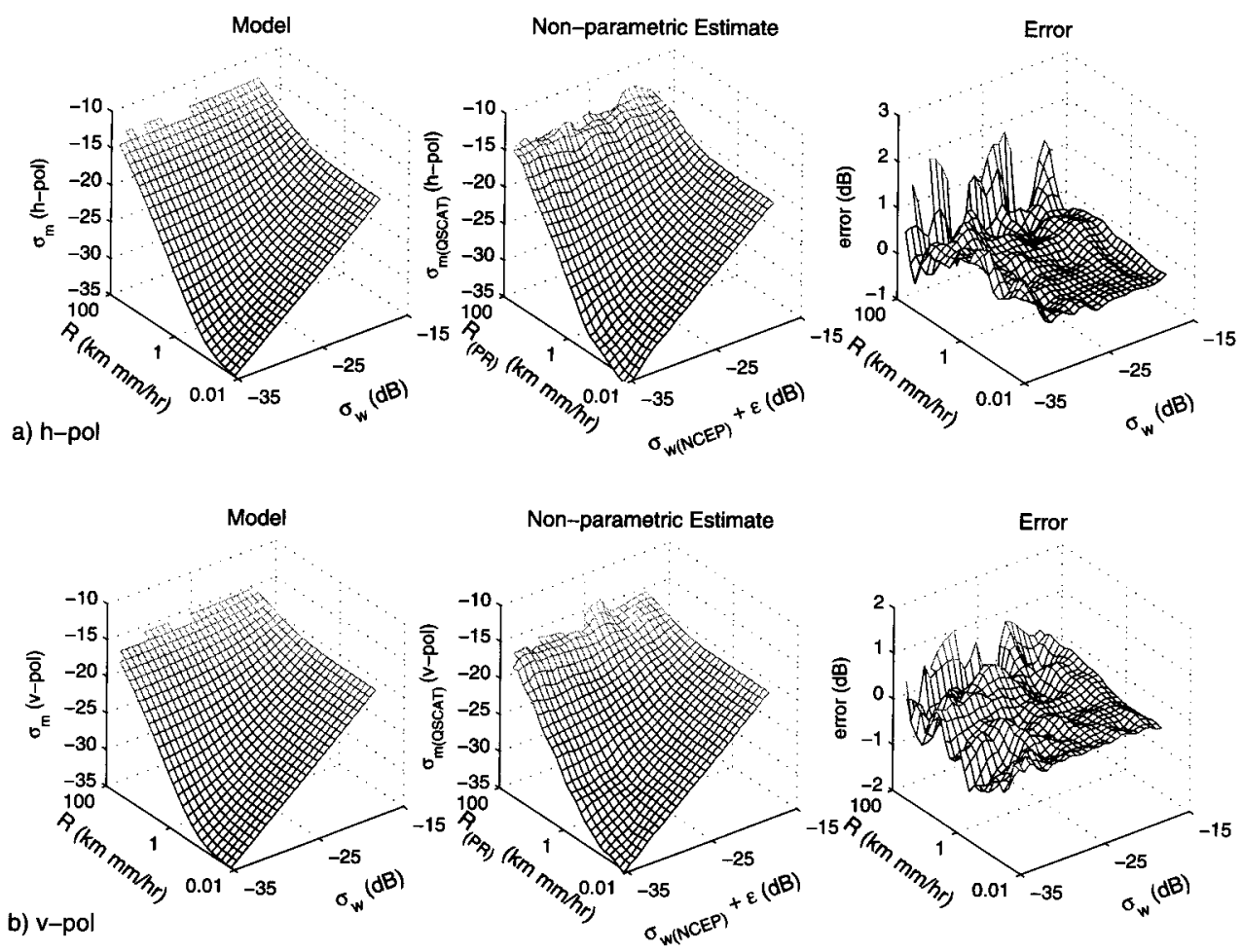

Figure 8. Nonparametric and combined rain effect models for (a) h-pol and (b) v-pol. Also shown is the error between parametric and nonparametric models.

sufficient to describe the effects of rain on the SeaWindsmeasured $\sigma$ to a high level of accuracy.

[38] For further comparison of the model to the data, we create a nonparametric estimate of $\sigma_{m}$ on a regular grid with axes of $\sigma_{w(N C E P)}+\epsilon$ and $R_{(P R)}$. The nonparametric estimate is formed using a two-dimensional Epanechnikov kernel. The nonparametric estimate, along with the quadratic combined rain effect model, is computed on the regular grid and shown in Figure 8 for h-pol and v-pol. Both h-pol and v-pol models are very close to the nonparametric estimate. The largest error occurs at high rain rates. However, there is less data at high rain rates, increasing the uncertainty in the estimate.

\subsection{Data Regimes}

[39] By examining the wind-rain model, we notice three distinct backscatter regimes. Regime one is where the rain backscatter $\sigma_{e}$ is large compared to the attenuated windinduced surface backscatter $\alpha_{r} \sigma_{w}$ and rain dominates the backscatter return. Regime two is where the backscatter from rain and wind effects are on the same order of magnitude. Regime three occurs where the wind-induced backscatter dominates rain effects. We can identify these regions by thresholding the ratio of $\sigma_{e}$ to the model estimate of $\sigma_{m}$. We define regime 1 by $\sigma_{e} / \sigma_{m}>.75$ and regime 3 as $\sigma_{e} / \sigma_{m}<.25$. Between these regimes is regime two. The regimes are plotted along with the combined rain effect model in Figure 9.

[40] The three regimes help us understand under what conditions rain and/or wind information can be extracted from SeaWinds on QuikSCAT data. Using the model, rain rates can readily be computed from data in regime 1 , but not from data in regime 3 . Wind information from data in regime 1 may be unobtainable, while current wind retrieval methods may be sufficient for accurate estimates from data in regime 3 . It is also likely that rain and wind information may be simultaneously retrieved from data in regime 2 by incorporating a rain model into the wind retrieval method (and improving the current scatterometer wind estimate).

[41] Of all h-pol SeaWinds measurements in the colocation data set with significant rain $(>0.1 \mathrm{~km} \mathrm{~mm} / \mathrm{hr})$, only $14 \%$ fall in regime 1 . About $41 \%$ fall in regime 2 , and $44 \%$ fall in regime 3 . For v-pol, about $7 \%$ of measurements fall in regime $1,29 \%$ in regime 2 , and $64 \%$ in regime 3. Assuming the 3-month co-location data set is representative, these percentages suggest that by including the rain model in the wind retrieval method, winds can be improved for a significant fraction of rain-corrupted measurements (data from regime 2). Also, because $36 \%$ to $56 \%$ of the measure-
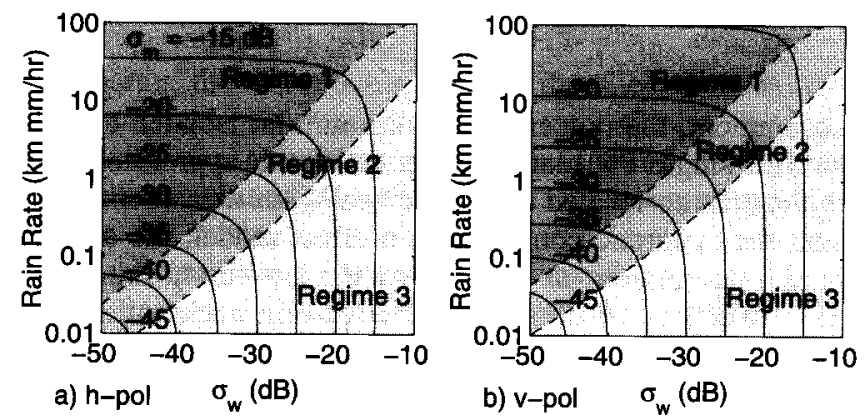

Figure 9. Backscatter regimes for SeaWinds on QuikSCAT as a function of rain rate and effective wind backscatter for (a) h-pol and (b) v-pol models. Also plotted is a contour plot of the combined rain effect model for $\sigma_{m}$. 
ments with significant rain fall into either regime 1 or 2 , we may be able to retrieve rain rates from nearly half of all SeaWinds rain-contaminated measurements. We again note that only $4 \%-10 \%$ of the measurements are affected by rain.

\section{Conclusions}

[42] Rain is one of the main sources of error in SeaWinds scatterometer winds. Current wind retrieval methods are limited by our knowledge of the effects of rain on scatterometer data. Although backscattering and attenuation from rain are successfully modeled, rain surface effects are not generally well understood.

[43] By synergistically combining TRMM PR and SeaWinds on QuikSCAT data, we have demonstrated that a simple low-order model is adequate for describing the wind/ rain interaction as a function of rain rate and nonraining effective wind $\sigma^{\circ}$. Also, our analysis suggests that the surface perturbation due to rain striking the water dominates the total scattering from rain for low to moderate rain rates $(<10 \mathrm{~km} \mathrm{~mm} / \mathrm{hr})$. Since backscatter from rain-induced waves significantly contribute to the total backscatter, surface effects must be included in the wind/rain model.

[44] In the wind/rain model, there are three distinct regimes. In the first regime, the rain dominates. It may be possible to directly calculate the rain rate from data in this regime. In the second regime, the signal from the rain and the wind are on the same order. Data from the second regime may be used to simultaneously retrieve wind and rain. In the third regime, the signal from the wind dominates and current wind retrieval techniques are adequate. These regimes help us understand where rain can be retrieved and where rain-contaminated wind can be corrected.

[45] The wind/rain model may be especially useful in connection with the SeaWinds on ADEOS II instrument launched in November 2002. SeaWinds on ADEOS II includes a dual-pol radiometer that measures rain rate at a high accuracy. Synergistic use of the radiometer and scatterometer via a rain model may significantly improve the wind estimation process.

\section{Appendix}

[46] Although we have oversimplified the error in $\sigma_{r}$ by modeling it as a simple multiplicative constant $\gamma$, it is of
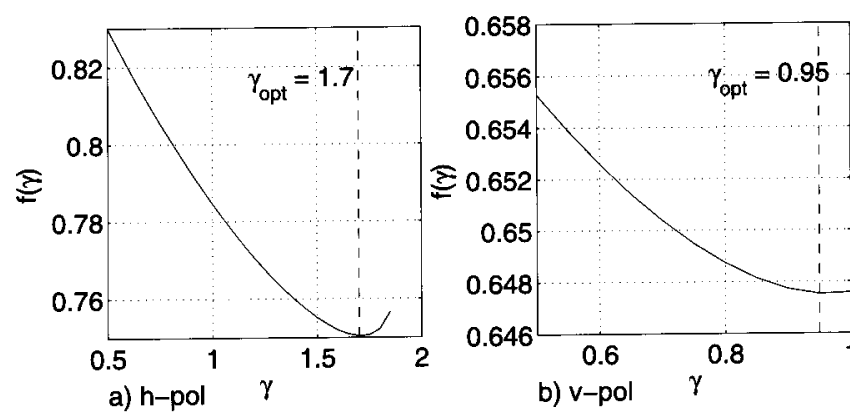

Figure 10. $\sigma_{s r}$ Objective function with respect to $\gamma$ (see text). The $\gamma$ that minimizes the objective function is displayed with a dashed line.
Table 3. Estimated Parameters of $\overrightarrow{\boldsymbol{\sigma}}_{s r}$ for h-pol and v-pol for the Optimum $\gamma$

\begin{tabular}{lcc}
\hline & h-pol $(\gamma=1.70)$ & v-pol $(\gamma=0.95)$ \\
\hline$x_{s r} \gamma(1)$ & -28.1 & -30.2 \\
$x_{s r} \gamma(2)$ & 0.93 & 1.01 \\
$x_{s r} \gamma(3)$ & -0.017 & -0.017 \\
\hline
\end{tabular}

value to consider the question "What $\gamma$ gives the best fit to the data and is the overall model sensitive to our choice of $\gamma$ ?" We approach this question by finding an optimum $\gamma$ that minimizes a least squares objective function given varying values of $\gamma$. The least squares objective function is a measure of the least squares error between the SeaWinds-measured $\sigma^{\circ}$ values and the model values given a certain $\gamma$,

$$
f(\gamma)=\sum_{i}\left(\sigma_{m}^{i}-\sigma_{m(C A L C)}^{i}(\gamma)\right)^{2}
$$

where $i$ is the data index and $\sigma_{m(C A L C)}(\gamma)$ is the modelcalculated $\sigma^{\circ}$ value given $\gamma$ and the corresponding model for $\sigma_{s r}$ The quadratic model for $\sigma_{s r}$ is used because it accounts for more of the variance than the linear model. Now, we compute $f(\gamma)$ at each valid value of $\gamma$. The objective function for both $h$-pol and v-pol is plotted against $\gamma$ in Figure 10. For h-pol, the objective function has a minimum where $\gamma=1.70$. For v-pol, the objective function has a minimum where $\gamma=0.95$. The values of $x_{s r}(n)$ corresponding to the optimum $\gamma$ are given in Table 3 . The optimum values for $\gamma$ suggest that the SeaWinds h-pol response to atmospheric rain is greater than the v-pol response. The shape of the objective function, however, suggests a high variance on our estimate, and that the overall model is not very sensitive to the exact choice of $\gamma$.

[47] Acknowledgments. The authors want to thank Michael Spencer and William Daffer at JPL for their assistance in co-locating the QuikSCAT/ TRMM PR data. This work was supported by the Ocean Vector Winds and TRMM science teams.

\section{References}

Bentamy, A., E. Autret, P. Queffeulou, and Y. Quilfen (2000), Intercomparison of ERS-2 and QuikSCAT winds, paper presented at IEEE International Geoscience and Remote Sensing Symposium, Inst. of Electr. and Electr. Eng., Honolulu, HI.

Bliven, L. F., and J. P. Giovanangeli (1993), Experimental study of microwave scattering from rain- and wind-roughened seas, Int. J. Remote. Sens., 14, 855-869.

Bliven, L. F., J. P. Giovanangeli, and G. Norcross (1989), Scatterometer directional response during rain, paper presented at IEEE International Geoscience Remote Sensing Symposium, Inst. of Electr. and Electr. Eng., Vancouver, B.C., Can.

Bliven, L. F., P. W. Sobieski, and C. Craeye (1997), Rain generated ringwaves: Measurements and modelling for remote sensing, Int. J. Remote Sens., 18, 221-228.

Chi, C., and F. K. Li (1988), Comparative study of several wind estimation algorithms for spaceborne scatterometers, IEEE Trans. Geosci. Remote Sens., 26, 115-121.

Contreras, R. F., W. J. Plant, W. C. Keller, K. Hayes, and J. Nystuen (2003), Effects of rain on Ku-band backscatter from the ocean, J. Geophys. Res., 108(C5), 3165, doi:10.1029/2001JC001255.

Craeye, C., P. W. Sobieski, and L. F. Bliven (1997), Scattering by artificial wind and rain roughened water surfaces at oblique incidences, Int. J. Remote Sens., 35, 532-539.

Draper, D. W., and D. G. Long (2002), An assessment of SeaWinds on QuikSCAT wind retrieval, J. Geophys. Res., 107(C12), 3212, doi:10.1029/2002JC001330. 
Freilich, M. H., and R. S. Dunbar (1993), Derivation of satellite wind model functions using operational surface wind analyses: An altimeter example, J. Geophys. Res., 98, 14,633-14,649.

Huddleston, J. N., and B. W. Stiles (2000), A multi-dimensional histogram rain flagging technique for SeaWinds on QuikSCAT, paper presented at IEEE International Geoscience and Remote Sensing Symposium, Inst. of Electr. and Electr. Eng., Honolulu, HI.

Iguchi, T., T. Kozu, R. Meneghini, J. Awaka, and K. Okamoto (2000), Rain profiling algorithm for the TRMM precipitation radar, J. Appl. Meteorol., $39,2038-2052$

Jelenak, Z., L. N. Connor, and P. S. Chang (2002), The accuracy of high resolution winds from QuikSCAT, paper presented at IEEE Internationa Geoscience and Remote Sensing Symposium, Inst. of Electr. and Electr. Eng., Toronto, Can.

Kozu, T., et al. (2001), Development of precipitation radar onboard the tropical rainfall measuring mission (TRMM) satellite, IEEE Trans. Geosci. Remote Sens., 39, 102-116.

Mears, C. A., D. Smith, and F. J. Wentz (2000), Detecting rain with QuikSCAT, paper presented at IEEE International Geoscience and Remote Sensing Symposium, Inst. of Electr. and Electr. Eng., Honolulu, HI.

Portabella, M., and A. Stoffelen (2001), Rain detection and quality control of SeaWinds, J. Atmos. Ocean. Technol., 18, 1171-1183.

Spencer, M. W., C. Wu, and D. G. Long (1997), Tradeoffs in the design of a spaceborne scanning pencil beam scatterometer: Application to SeaWinds, IEEE Trans. Geosci. Remote Sens., 35, 115-126.
Stiles, B. W., and S. Yueh (2002), Impact of rain on spaceborne Ku-band wind scatterometer data, IEEE Trans. Geosci. Remote Sens., 40, 19731983

Stiles, B. W., B. D. Pollard, and R. S. Dunbar (2002), Direction interval retrieval with thresholded nudging: A method for improving the accuracy of QuikSCAT winds, IEEE Trans. Geosci. Remote Sens., 40, 7989.

Ulaby, F. T., R. K. Moore, and A. K. Fung (1981), Microwave Remote Sensing Active and Passive, Artech House, Norwell, Mass.

Wand, M., and M. Jones (1995), Kernel Smoothing, Chapman and Hall, New York.

Weissman, D. E., M. A. Bourassa, and J. Tongue (2002), Effects of rain rate and wind magnitude on SeaWinds scatterometer wind speed errors J. Atmos. Oceanol. Technol., 19, 738-746.

Wentz, F. J., and D. K. Smith (1999), A model function for the oceannormalized radar cross section at $14 \mathrm{GHz}$ derived from NSCAT observations, J. Geophys. Res., 104, 11,499-11,514.

Wentz, F. J., M. H. Freilich, and D. K. Smith (1998), NSCAT-2 geophysical model function, Eos Trans. $A G U, 79(45)$, Fall Meet. Suppl., F417.

D. W. Draper and D. G. Long, Microwave Earth Remote Sensing (MERS) Lab, Brigham Young University, 459 CB, Provo, UT 84602, USA (draperd@et.byu.edu; long@ee.byu.edu) 